\title{
Nurse-led advance care planning with older people who have end-stage kidney disease: feasibility of a deferred entry randomised controlled trial incorporating an economic evaluation and mixed methods process evaluation (ACReDiT)
}

Peter O'Halloran ${ }^{1 *}$ (D), Helen Noble ${ }^{1}$, Kelly Norwood ${ }^{2}$, Peter Maxwell ${ }^{3,4}$, Fliss Murtagh ${ }^{5}$, Joanne Shields ${ }^{4}$, Robert Mullan ${ }^{6}$, Michael Matthews ${ }^{1,6}$, Christopher Cardwell$^{7}$, Mike Clarke ${ }^{7}$, Rachael Morton ${ }^{8}$, Karan Shah ${ }^{8}$, Trisha Forbes ${ }^{1}$ and Kevin Brazil ${ }^{1}$

\begin{abstract}
Background: Advance Care Planning is recommended for people with end-stage kidney disease but evidence is limited. Robust clinical trials are needed to investigate the impact of advance care planning in this population. There is little available data on cost-effectiveness to guide decision makers in allocating resources for advance care planning. Therefore we sought to determine the feasibility of a randomised controlled trial and to test methods for assessing cost-effectiveness.

Methods: A deferred entry, randomised controlled feasibility trial, incorporating economic and process evaluations, with people with end-stage kidney disease, aged 65 years or older, receiving haemodialysis, in two renal haemodialysis units in Northern Ireland, UK. A nurse facilitator helped the patient make an advance care plan identifying: a surrogate decision-maker; what the participant would like to happen in the future; any advance decision to refuse treatment; preferred place of care at end-of-life.
\end{abstract}

(Continued on next page)

\footnotetext{
* Correspondence: p.ohalloran@qub.ac.uk

'School of Nursing and Midwifery, Queen's University Belfast, Medical Biology Centre, 97 Lisburn Road, Belfast BT9 7BL, UK
}

Full list of author information is available at the end of the article

C C The Author(s). 2020 Open Access This article is licensed under a Creative Commons Attribution 4.0 International License, which permits use, sharing, adaptation, distribution and reproduction in any medium or format, as long as you give appropriate credit to the original author(s) and the source, provide a link to the Creative Commons licence, and indicate if changes were made. The images or other third party material in this article are included in the article's Creative Commons licence, unless indicated otherwise in a credit line to the material. If material is not included in the article's Creative Commons licence and your intended use is not permitted by statutory regulation or exceeds the permitted use, you will need to obtain permission directly from the copyright holder. To view a copy of this licence, visit http://creativecommons.org/licenses/by/4.0/ The Creative Commons Public Domain Dedication waiver (http://creativecommons.org/publicdomain/zero/1.0/) applies to the data made available in this article, unless otherwise stated in a credit line to the data. 
(Continued from previous page)

Results: Recruitment lasted 189 days; intervention and data collection 443 days. Of the 67 patients invited to participate 30 (45\%) declined and 36 were randomised to immediate or deferred advance care plan groups. Twenty-two (61\%) made an advance care plan and completed data collection at 12 weeks; 17 (47.2\%) were able to identify a surrogate willing to be named in the advance care plan document. The intervention was well-received and encouraged end-of-life conversations, but did not succeed in helping patients to fully clarify their values or consider specific treatment choices. There was no significant difference in health system costs between the immediate and deferred groups.

Conclusions: A trial of advance care planning with participants receiving haemodialysis is feasible and acceptable to patients, but challenging. A full trial would require a pool of potential participants five times larger than the number required to complete data collection at 3 months. Widening eligibility criteria to include younger (under 65 years of age) and less frail patients, together with special efforts to engage and retain surrogates may improve recruitment and retention. Traditional advance care planning outcomes may need to be supplemented with those that are defined by patients, helping them to participate with clinicians in making medical decisions.

Trial registration: Registered December 16, 2015. ClinicalTrials.gov Identifier: NCT02631200.

Keywords: Advance care planning, Advance directives, End-of-life care, End-stage Kidney disease, Feasibility studies, Palliative care, Randomized controlled trial, Renal Dialysis

\section{Background}

In 2017, more than 25,000 individuals in the United Kingdom (UK) were receiving haemodialysis for end-stage kidney disease (ESKD) [1]. This is mirrored worldwide, with over 2.5 million people receiving renal replacement therapy [2]. Patients with ESKD characteristically suffer from a wide range of co-morbidities, including hypertension, diabetes, heart failure, chronic pulmonary disease, atrial fibrillation, depression, and dementia [3]. Consequently, they are at high risk for hospitalisation $[4,5]$ and earlier death $[6,7]$. Nevertheless, many patients with ESKD do not discuss issues such as cardiopulmonary resuscitation, Intensive Care Unit admission, withdrawal of dialysis, involvement of specialist palliative care, end-of-life care, and preferred place of death with healthcare professionals $[8,9]$. Many persons with ESKD also have unmet palliative care needs $[10,11]$. In this context, advance care planning (ACP) may enable shared decisionmaking among patients, their families and healthcare professionals.

ACP is a process of discussions between a patient, their family and healthcare professionals to clarify values, treatment preferences and goals of end-of-life care [12]. In a variety of settings, ACP is associated with important benefits, including reduced hospitalisations increased uptake of palliative care services, improved quality of life, decreased anxiety and depression among family members, and care that is more in keeping with patient preferences [13-17]. Consequently, ACP is widely recommended for patients with ESKD [18-20]. However, recent systematic reviews found sparse, low-quality data to support the benefits of ACP in this population $[12,21]$. Robust clinical trials are needed to investigate the impact of ACP on patient and surrogate decision-making and emotional burden; enactment of patient preferences for end-of-life care; recourse to life-prolonging treatments; and use of palliative care services and hospice care. There is also little available data on cost-effectiveness to guide decision makers in allocating resources for ACP [22]. Given that implementation success is heavily influenced by a complex network of patient, staff, organisational and cultural factors [23], and following guidance from the UK Medical Research Council on the evaluation of complex interventions [24], we tested intervention and research processes related to ACP for patients with ESKD. This work will inform a larger scale randomised controlled trial, economic evaluation and process evaluation of ACP for people receiving haemodialysis. We planned deferred entry for the control group, because we wanted to gauge whether patients allocated to this group would be distressed at having to wait for the intervention once the issue of ACP had been raised with them.

\section{Aim}

To determine the feasibility of conducting a deferred entry randomised controlled trial of ACP with patients who have ESKD, incorporating an economic evaluation and mixed methods process evaluation.

Our objectives were to investigate:

- Recruitment, retention and participation rates

- Acceptability of the intervention to patients, their relatives, and healthcare professionals

- Optimal systems for delivering ACP, including the recruitment and training of clinical staff to facilitate $\mathrm{ACP}$

- Effect sizes that might help inform sample-size estimates for a full trial

- Randomisation procedures and participants' willingness to enter a deferred entry trial 
- The suitability of a twelve-week deferral period and a nine-month process evaluation

- Suitability and timing of survey instruments and outcome measures

- Time needed to collect and analyse data

- Estimated resource use and costs of delivering ACP and methods for assessing costs, benefits and costeffectiveness

\section{Methods}

\section{Patient and public involvement}

At the development stage of the trial, we met with patient representatives from a local charity, the Northern Ireland Kidney Patient Association, to discuss the acceptability of ACP, strategies for implementation, and the suitability of ACP and trial documentation. The steering group also included a patient with ESKD, who was invited to co-design the trial processes.

\section{Trial design}

A deferred entry [25, 26], parallel group randomised controlled feasibility trial in which patients and their nominated surrogate were allocated in a 1:1 ratio to either immediate or deferred entry groups. Participants in the deferred entry group had outcomes measured contemporaneously with the immediate entry group but received the intervention 12 weeks after baseline data collection. This allowed a comparison at 12 weeks between those who had received the intervention at the beginning of the trial (the immediate group) and those who had not yet received it (the deferred group), as in a standard randomised controlled trial (RCT).

\section{Participants and settings}

Participants were recruited from two haemodialysis units in Northern Ireland (NI), UK. Patients were eligible for the trial if they were English speaking; aged 65 years or older; with ESKD and receiving haemodialysis, with capacity to understand, retain, and weigh the necessary information in English and communicate their decisions; identified by their consultant nephrologist as having either worsening symptoms, functional decline, or two or more co-morbidities; and not expected to die in the next 3 months. Surrogates (a relative or friend identified by the patient as their nominated surrogate and willing to represent the patient's wishes should they lose decisionmaking capacity, although without formal power of attorney) were eligible if they were aged 18 years or older and able to read, write, and speak English.

The sampling frame was patients meeting initial criteria (aged 65 or older and receiving haemodialysis) registered with the participating units. Patients on this list were screened against the full eligibility criteria by their nephrologist and a nurse trained as an ACP facilitator.
Eligible patients were approached by their nephrologist to assess their interest in participating. Interested patients were given patient information packs for themselves and a surrogate. The ACP nurse returned to the patient 2-7 days later to seek their consent. Consenting patients were asked if they would like support from an 'expert patient' and to involve a surrogate. Surrogates could contact the research team directly using a dedicated phone number or email address, or a form and reply-paid envelope. Participating surrogates were asked to avoid discussing the details of the ACP with the patient until the research started. Surrogates could be involved with the ACP but not in the research if they preferred.

\section{Intervention}

The intervention was offered in the outpatient units when the patient attended for haemodialysis. The lead professionals were seven experienced nurses (with 2045 years as registered nurses, all with post-registration courses in renal nursing, and four with counselling qualifications) working in the two haemodialysis units, who had volunteered for half-day training as ACP facilitators offered by a local health and social care trust using 'Sage \& Thyme' Communication Skills Training on dealing with people in distress [27]. Patients were given the opportunity to receive support from 'expert patients' during the ACP process. These were five people with ESKD who were in receipt of a kidney transplant or on dialysis and who volunteered for a 2 hour training session delivered by the team doing the ACP training, focused on understanding ACP and the role of the expert patient. The expert patient was available to act as a conversation partner with patients making an $\mathrm{ACP}$, with support from an identified ACP nurse. A senior nurse in each unit, supported by a designated consultant nephrologist, oversaw the intervention process. Before the trial began, patients attending for dialysis were handed a flyer with a brief description of the research telling them that their doctor or nurse might approach them about this in the following weeks.

1. Participants were offered the opportunity to complete a plan by an ACP nurse, who discussed the process with them using the booklet, "Your life and your choices: plan ahead," produced by the NI Public Health Agency and Macmillan Cancer Support. At this stage, the ACP nurse asked the participant to complete the 'Record of my wishes' form found in the booklet, intended to help patients organise their thoughts.

2. One-to-two weeks later, the patient completed an ACP document (Advance Care Planning Summary) with the help of the ACP nurse, and a trained 
expert patient who (if the patient wished) provided peer support at the time of ACP completion and subsequently by telephone, assisted where necessary by the ACP nurse.

3. The patient's surrogate was invited to take part in the discussion if the patient wished.

4. The ACP document was one recommended for use throughout NI ("A record of my wishes", developed by the NI Palliative and End of Life Care Implementation Group), which records an Advance Care Planning Summary, alongside the identification of a nominated surrogate decisionmaker. The plan set out:

a) What the patient would like to happen in the future

b) What the patient would not want to happen

c) If it was already made: a record of the presence and broad content of an advance decision to refuse treatment (ADRT): a legally binding statement that allows a patient to refuse specific medical treatments if they lose capacity [13]; and any do not resuscitate (DNR) decision document.

d) Preferred place of care at the end-of-life

e) Any special requests

Patients were encouraged to keep the ACP with them and to make it available to anyone caring for them. A summary was kept with their medical notes and copied to their General Practitioner (primary care physician), and community nursing services. The ACP was reviewed with the ACP nurse after two and 12 weeks, or if circumstances changed, or the patient changed their mind about preferences. Participants in the deferred entry group were offered the intervention 12 weeks after baseline data collection, following collection of their 12week outcome data.

\section{Outcomes}

Outcomes were collected in the same way in the immediate entry and deferred entry groups. All outcomes were measured by trained research assistants who were aware of group allocation (Table 1).

i. Quality of life as measured by the Kidney Disease Quality of Life instrument - Short Form (KDQOL$\left.36^{\mathrm{Tm}}\right)$, a 36-item Likert-type scale where each item is scored on a range of $0-100$ and higher scores reflect better quality of life [28].

ii. Degree of cognitive impairment as measured by the Isaacs Set Test (IST 15) [29].

iii. Degree of anxiety, depression, well-being, functioning and risk as measured by the Clinical Outcomes in Routine Evaluation measure (CORE 34) a 34item Likert-type scale scored on a 5-point scale ranging from 0 (not at all) to 4 (most or all the time). Higher scores indicate greater distress [30]. Mean scores from reference groups are 1.86 (SD 0.75) for those referred to psychiatric services and 0.76 (SD 0.59) for the general population [31].

iv. Degree to which the patient felt that they had shared in decision-making about their care as measured by the Patient Experience of Shared Decision Making (SHARED) instrument [32], a ten-item

Table 1 Schedule of trial interventions and assessments

\begin{tabular}{|c|c|c|c|c|}
\hline \multirow{2}{*}{$\begin{array}{l}\text { Time } \\
\text { points }\end{array}$} & \multicolumn{2}{|l|}{ Immediate entry } & \multicolumn{2}{|l|}{ Deferred entry } \\
\hline & Patient $^{a}$ & Surrogate & Patient $^{\mathrm{a}}$ & Surrogate \\
\hline \multirow[t]{2}{*}{$\begin{array}{l}\text { T1 } \\
\text { Baseline }\end{array}$} & $\begin{array}{l}\text { IST } 15 \\
\text { CORE } 34 \\
\text { KDQOL-36 } \\
\text { SHARED }\end{array}$ & ACP agreement questionnaire & $\begin{array}{l}\text { IST } 15 \\
\text { CORE } 34 \\
\text { KDQOL-36'M } \\
\text { SHARED }\end{array}$ & \\
\hline & ACP intervention & ACP intervention & & \\
\hline $\begin{array}{l}\text { T2 } \\
2 / 52\end{array}$ & $\begin{array}{l}\text { ACP 1st review } \\
\text { CORE } 34 \\
\text { SHARED }\end{array}$ & ACP agreement questionnaire before review & $\begin{array}{l}\text { CORE } 34 \\
\text { SHARED }\end{array}$ & \\
\hline \multirow[t]{2}{*}{$\begin{array}{l}\text { T3 } \\
12 / 52\end{array}$} & \multirow{2}{*}{$\begin{array}{l}\text { ACP 2nd review } \\
\text { CORE } 34 \\
\text { KDQOL-36 } \\
\text { SHARED } \\
\text { SHARE }\end{array}$} & ACP agreement questionnaire after review & $\begin{array}{l}\text { CORE } 34 \\
\text { KDQOL-36 } \\
\text { SHARED }\end{array}$ & ACP agreement questionnaire \\
\hline & & & ACP intervention & ACP intervention \\
\hline $\begin{array}{l}\text { T4 } \\
24 / 52\end{array}$ & & & $\begin{array}{l}\text { ACP review } \\
\text { CORE } 34 \\
\text { KDQOL-36 } \\
\text { SHARED }\end{array}$ & ACP agreement questionnaire after review \\
\hline
\end{tabular}


Likert-type scale ranging from 'Disagree strongly' to 'Agree strongly'. Scores are out of 20, with one point for 'Agree', two for 'Agree strongly', and no points for disagreement. Higher scores indicate more sharing.

v. Agreement between the patient and surrogate in terms of the patient's preferences, measured by asking the carer (by telephone if they were not present) to make an independent assessment of the patient's preferences in relation to the key information covered by the ACP intervention (a-e above), before taking part in the ACP and at two and 12 weeks post ACP.

vi. An economic evaluation of costs and benefits of the ACP intervention using data from the following sources:

a. Electronic hospital admissions data for each patient

b. Patient completed cost diaries documenting personal health and social care resource use. These were paper diaries to be filled in weekly with printed sections for the patient - with help from a research assistant if required - to provide details of formal care (e.g. from a home care worker) or visits from health care professionals received in the home; contacts with community doctors or nurses; use of hospital or residential services. Patients were asked to record the number and estimated length of contacts.

c. Health-related quality of life using the SF-6D utility measure, derived from the SF-12 (contained within the KDQOL-36 ${ }^{\text {ma }}$ questionnaire).

d. Staff training costs.

e. Staff intervention time for each patient, documented by staff delivering ACP.

\section{Sample size}

We aimed to recruit 40 patient-surrogate dyads. Assuming $25 \%$ attrition, this sample size provided sufficient numbers to allow feasibility to be estimated [33, 34].

\section{Randomisation}

The random allocation sequence was generated by a statistician unconnected with recruitment, using randomisation software, into blocks of random sizes from two to eight. Block sizes were concealed from the clinical staff involved in recruitment. Allocations were concealed using sequentially numbered, opaque, sealed envelopes, held by a research team member unconnected with recruitment or data collection. These envelopes were opened sequentially following patient consent and baseline data collection.

\section{Blinding}

Analysis of outcome data was carried out by a statistician and health economists blinded to allocation. However, it was not possible to blind patients, their surrogates, or clinical staff to the ACP intervention. Neither was it feasible in a study with limited resources to blind outcome assessment.

\section{Analytical methods}

Baseline data were analysed using descriptive statistics. The proportion of patients eligible for inclusion, agreeing to participate and completing the study was calculated along with exact binomial 95\% confidence intervals (CIs). Analysis of covariance was used to compare the mean difference (and 95\% CIs) in outcome variables at 12 weeks between the intervention and control group adjusting for baseline values [35]. Paired t-tests were conducted to compare changes in outcome measures within the immediate entry and deferred entry groups. Statistical analyses were conducted using STATA SE software, v14.0 [36].

\section{Economic analysis}

A cost-consequence analysis was undertaken alongside the randomised trial.

We tabulated the mean per patient volume of healthsystem resource use (healthcare activity) and mean costs per patient. The difference in costs between groups at 12 weeks was calculated. Standard deviations and 95\% $\mathrm{CI}$ were used to describe precision estimates. Unit costs were informed by NHS 2017/18 reference costs and market rates. Costs are presented in 2018 Great Britain Pounds sterling $(£)$ and discounting was not applied.

The mean preference-based quality of life (utility) for ea13-ch group was calculated at 12 weeks, using UK tariffs for the SF-6D, and adjusted for baseline values. Missing data were clearly reported, and complete case analysis used in the first instance. To assess uncertainty in utility estimates, a sensitivity analysis imputing the last value carried forward (if appropriate) was undertaken. Quality adjusted life years (QALYs) were calculated in a similar fashion for each group. STATA SE software (v14.0) was used for the economic analysis and reporting was consistent with the Consolidated Health Economic Evaluation Reporting Standards (CHEERS) checklist [37]. As it is unclear whether a cost per QALY framework is appropriate for decision making about interventions near the end of life, costs and outcomes were not aggregated into a cost-effectiveness ratio for this feasibility study.

\section{Process Evaluation}

The process evaluation was informed by the findings of a realist review on implementation of $\mathrm{ACP}$ with patients 
with ESKD [23]. In relation to the trial, this was a mixed-methods sequential explanatory approach in which the qualitative data are collected after the quantitative data to help explain how the quantitative results have come about [38]. Research assistants observed staff training for ACP. They also developed a process map [39] of the personnel and systems involved in managing ACP with help from key nursing and medical staff who had delivered the intervention from the unit recruiting the majority of participants. Research assistants met with medical and nursing staff who had delivered the intervention. These staff described in detail their real-world experience of implementation, outlining all the necessary steps for delivering ACP in practice. Qualitative data was collected from those delivering and making ACP, using a semi-structured guide, to elicit their experience of ACP (what they hoped ACP would achieve; their concerns and feelings) and their views on barriers and facilitators of implementation (the written materials used; what helped or hindered; what could be done better). We convened focus groups with four "Sage and Thyme" ACP trainers, and three ACP nurses. We also interviewed four nephrologists, six patients and five surrogates. Interviews and focus groups were digitally recorded and transcribed verbatim. Each piece of interview and other data was coded in relation to the initial theory derived from the realist review to allow indexing and retrieval in a suitable database. The qualitative data were reviewed by members of the research team searching for configurations that support, contradict and link theory, seeking to explain outcomes.

\section{Ethical approval}

Ethical approval was provided by the Office for Research Ethics Committees, Northern Ireland. REC reference: 16/NI/0043; Protocol number: B16/06; IRAS project ID: 193402. All participants gave written informed consent. ClinicalTrials.gov Identifier: NCT02631200. The trial adheres to CONSORT guidelines for randomised pilot and feasibility trials [40].

\section{Results}

Recruitment and time needed to collect and analyse data The research took place between December 2016 and August 2018. Recruitment lasted 189 days, with an intervention and data collection period of 443 days. Patients identified from electronic records as meeting initial recruitment criteria numbered 120. Of these, 99 were screened against the full eligibility criteria by their nephrologist and a nurse trained as an ACP facilitator, and 32/99 were excluded: seven lacked mental capacity; six were sight or hearing impaired; six had a recent acute illness or decline; four had less than 3 months life expectancy; two had not experienced either worsening symptoms, functional decline, or two or more comorbidities; one had limited English, and for six patients no reason was given. Sixty-seven of the 99 patients $(68$, 95\% CI 58-77\%) were invited to participate and 30 (45\%) declined. Of the 24 patients who gave a reason for non-participation, 11 (46\%) objected to ACP; four (17\%) did not want to distress their spouse by raising ACP; three $(13 \%)$ did not want the trouble of answering questions; one did not want to choose a surrogate; and the remaining five did not disclose specific reasons. Thirtyseven patients consented to join the trial, with one patient withdrawing before baseline data collection at $\mathrm{T} 1$, leaving 36 (54\% of those invited, 95\% CI 41-66\%) to be randomised: 17 to the immediate intervention group and 19 to the deferred intervention group. The planned sample size was almost reached (Fig. 1).

\section{Retention and participation}

Of all 36 participants, 22 (61, 95\% CI 44-77\%) made an ACP and completed data collection at T3. In the immediate entry group, 13 received the intervention and completed data collection at T2 (2 weeks); with 10 completing data collection at T3 (12 weeks). In the deferred group, 18 entered the follow-up period and completed data collection at T2; with 12 completing data collection at T3, 9 receiving deferred ACP, and 7 completing data collection at T4 (24 weeks). Only one patient chose to involve an expert patient. By T4, 17 patients (47\%) remained in the trial and 19 (53\%) had left, 12 of these from the deferred group. Four of these 19 patients had died; six felt physically unable to complete the questionnaires; one received a transplant; one felt too anxious about the research process; one left because of family ill health; and six did not specify a reason for leaving.

Surrogate involvement was low, with 17 of 36 patients (47.2\%) able to formally identify a surrogate willing to be named in the ACP document, and 10 surrogates fully participating in the ACP process and providing information on their understanding of the patient's preferences (Table 2).

\section{Baseline data}

Baseline data are presented in Table 3. The groups were broadly similar with minor imbalances consistent with randomisation of a small number of participants. All participants were white British or Irish.

\section{Outcome measures}

Outcome measures are presented in Table 4. KDQOL$36^{\mathrm{m}}$ scores were commensurate with those of older adults receiving dialysis in the United States [41]. Between $\mathrm{T} 1$ and T3, KDQOL-36 ${ }^{\mathrm{TM}}$ scores fell in the immediate group and rose in the deferred group, and these 


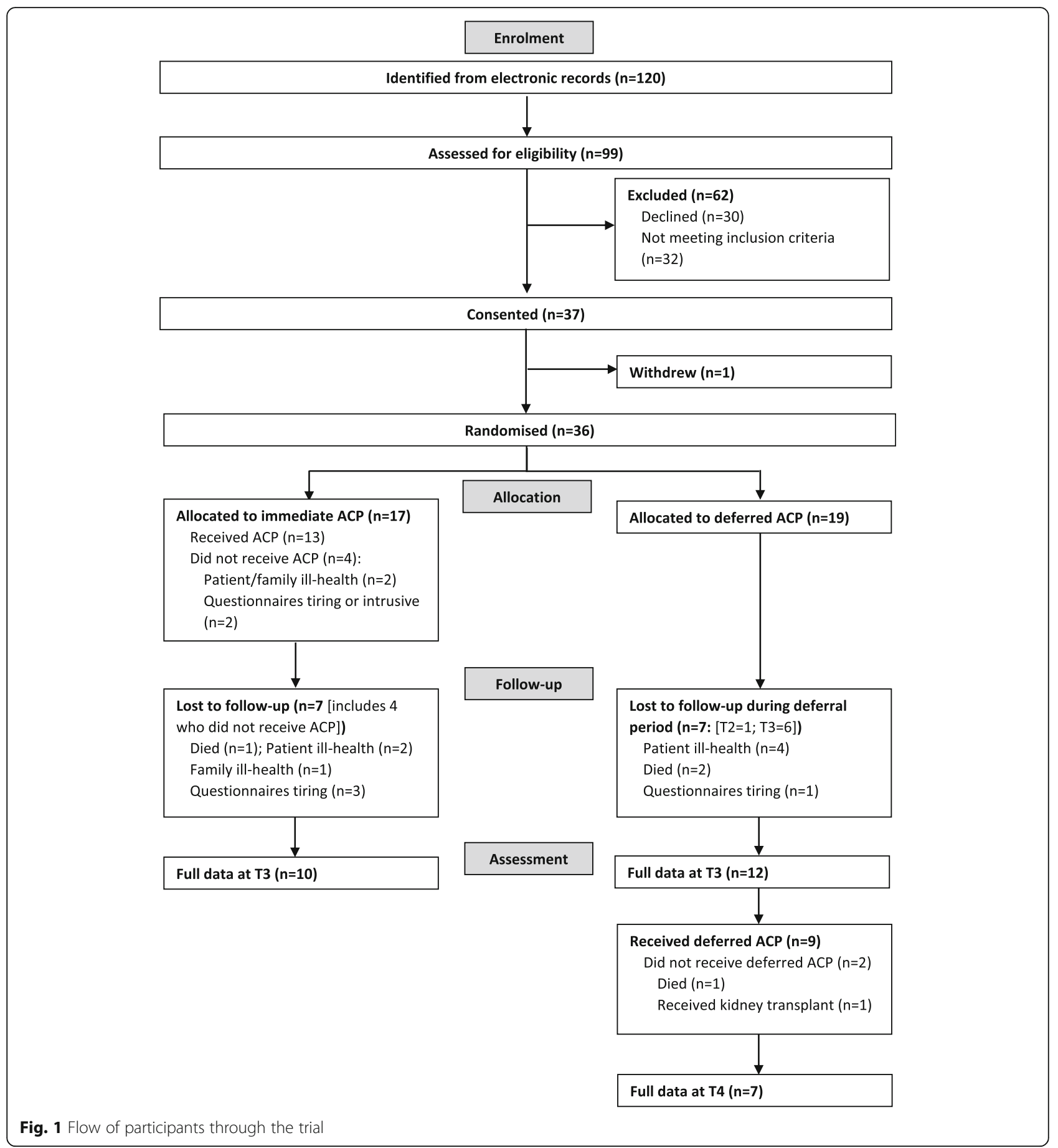

changes were statistically significant in the Effects, Burden and SF12 physical subscales. CORE34 scores were low compared with the general population [30]. They fell in the deferred group between $\mathrm{T} 1$ and $\mathrm{T} 3$ but this change was not statistically significant.

Many patients found the SHARED tool difficult to use because the baseline measure required them to think of a time when they had made a decision with a healthcare professional, and few could identify such an occasion. Consequently, few completed this measure.

\section{Cost consequence analysis}

Admissions data for the study period were readily available from electronic hospital records at each site. Patients were able to provide information for the cost diaries but most did not record data at home and instead 
Table 2 Surrogate participation

\begin{tabular}{llll}
\hline & Immediate & Deferred & All participants \\
\hline Patients & 17 & 19 & $36(100 \%)$ \\
Surrogate named in ACP document & 10 & 7 & $17(47.2 \%)$ \\
Participated in ACP process & 7 & 3 & $10(27.8 \%)$ \\
Did not participate in ACP & 3 & 4 & $7(19.4 \%)$ \\
Converged $^{a}$ & 3 & 0 & $3(8.3 \%)$ \\
No convergence & 4 & 3 & $7(19.4 \%)$
\end{tabular}

${ }^{a}$ Converged = surrogate's understanding of ACP converged with patient's on at least one dimension of ACP

waited until attending dialysis to report this information to research assistants. Initially, we recorded these data weekly but we changed to monthly because so few events were reported. Clinical staff recorded their time in minutes spent at each stage of the research and for the ACP implementation.

Resource use was categorised into ACP intervention costs: nephrologist and nursing staff time for training and implementation, and expert patient facilitation time (Table 5); and health system costs: hospital admissions, formal home care, GP visits, and residential aged care services (Table 6). The mean time taken by nephrologists to introduce ACP was 16 $\mathrm{min}$, and nurses $19 \mathrm{~min}$. The mean nursing time taken to deliver the ACP was 74 min. Following randomisation, the average length of stay for those admitted to hospital over 12 weeks was 10 days for the immediate group and 9 days for the deferred group. There was no statistically significant difference in health system resource use or costs between the immediate and deferred group for any cost category.

The mean quality of life (utility) for the immediate intervention group decreased by 0.01 at 12 weeks, while it increased by 0.03 for the deferred group. However, neither change was statistically significant and there was no significant difference in utility between groups at 12 weeks when adjusted for baseline values (Table 7). A similar result was observed for QALYs.

Table 3 Baseline characteristics

\begin{tabular}{|c|c|c|c|}
\hline Description & Immediate entry $(n=17)$ & Deferred entry $(n=19)$ & All $(n=36)$ \\
\hline Age (years) ${ }^{a}$ & $75.6(6.81)$ & $73.2(5.01)$ & 74.9 (6.89) \\
\hline Age range (years) & $67-92$ & $65-83$ & \\
\hline Sex (male) & $14(82 \%)$ & $16(84 \%)$ & \\
\hline RRT $^{b}$ (years) $^{c}$ & $1(0.5-4.0)$ & $3(1.0-7.0)$ & $2(1.0-5.5)$ \\
\hline Number of comorbidities ${ }^{c}$ & $2(1.0-4.5)$ & $3(2.0-4.0)$ & $2(1.0-4.0)$ \\
\hline Diabetes & $7(41 \%)$ & $5(26 \%)$ & \\
\hline Isaac's Set Test ${ }^{a}$ & $31.7(7.4)$ & $30.6(6.3)$ & $31.1(6.7)$ \\
\hline CORE34 $4^{\mathrm{a}}$ & $0.48(0.43)$ & $0.75(0.57)$ & $0.62(0.52)$ \\
\hline \multicolumn{4}{|l|}{ KDQOL-36 ${ }^{\mathrm{TM}}$} \\
\hline Symptoms ${ }^{a}$ & $77.1(18.6)$ & $67.9(23.1)$ & $72.2(21.3)$ \\
\hline Effects $^{a}$ & $86.8(12.1)$ & $65.8(25.6)$ & $75.7(22.7)$ \\
\hline Burden $^{a}$ & $45.6(27.5)$ & $40.8(30.2)$ & $43.1(28.7)$ \\
\hline SF12 physical $^{a}$ & $37.3(4.8)$ & $30.7(10.46)$ & $33.8(8.8)$ \\
\hline SF12 mental ${ }^{a}$ & $46.8(10.7)$ & $51.3(12.4)$ & $49.2(11.7)$ \\
\hline SHARED score ${ }^{a}$ & $11.5(6.9)^{\mathrm{e}}$ & $8.3(4.1)^{\mathrm{e}}$ & $9.3(5.2)$ \\
\hline University degree & $5(29 \%)$ & $1(5 \%)$ & \\
\hline Household income $^{d}$ & $£ 10-20,000(£ 10-60,000)$ & $£ 10-20,000(£ 10-70,000)$ & \\
\hline Renal Unit 1 & $13(76 \%)$ & 16 (84\%) & \\
\hline
\end{tabular}

${ }^{\mathrm{a}}$ Mean (standard deviation)

${ }^{\mathrm{b}}$ Renal replacement therapy

'Median (inter-quartile range)

dMedian, reported in increments of $£ 10,000$ (range)

e Data from 6 patients in immediate group and 13 in deferred group 
Table 4 Outcome measure scores at baseline T1 and T3 (including only people who contribute to complete case analysis)

\begin{tabular}{|c|c|c|c|c|c|c|c|c|}
\hline \multirow[t]{2}{*}{ Variable } & \multicolumn{3}{|c|}{ Immediate $(n=10)$} & \multicolumn{3}{|c|}{ Deferred $(n=12)$} & \multirow[b]{2}{*}{$\begin{array}{l}\text { Adjusted diff in mean } \\
(95 \% \mathrm{Cl})\end{array}$} & \multirow[b]{2}{*}{ ANCOVA } \\
\hline & Baseline T1 & T3 & Within group $P$ & Baseline T1 & T3 & Within group $P$ & & \\
\hline \multicolumn{9}{|l|}{ KDQOL-36 ${ }^{\mathrm{TM}}$} \\
\hline Symptoms ${ }^{a}$ & $81.7(17.1)$ & $75.4(13.3)$ & 0.116 & $71.4(20.7)$ & $78.3(19.2)$ & 0.154 & $-9.3(-20.7,2.1)$ & 0.103 \\
\hline Effects $^{a}$ & 89.1 (12.8) & $78.4(16.0)$ & 0.024 & $68.0(24.1)$ & 73.4 (21.6) & 0.084 & $-12.2(-23.3,-1.1)$ & 0.033 \\
\hline Burden $^{a}$ & 56.9 (19.6) & $46.9(23.8)$ & 0.100 & $41.7(23.9)$ & $55.2(25.7)$ & 0.001 & $-22.6(-36.0,-9.1)$ & 0.002 \\
\hline SF12 physical $^{\mathrm{a}}$ & $38.3(4.7)$ & $31.5(9.5)$ & 0.008 & $33.2(11.2)$ & $34.9(13.0)$ & 0.513 & $-8.4(-15.8,-1.0)$ & 0.029 \\
\hline SF12 mental ${ }^{\mathrm{a}}$ & $51.7(6.2)$ & $53.3(6.9)$ & 0.608 & $53.1(10.7)$ & $52.4(6.9)$ & 0.816 & $1.2(-5 \cdot 0,7.3)$ & 0.698 \\
\hline CORE34 & $0.4(0.4)$ & $0.4(0.3)$ & 0.293 & $0.6(0.3)$ & $0.4(0.3)$ & 0.01 & $0.2(-0.0,0.3)$ & 0.056 \\
\hline SHARED ${ }^{c}$ & $14.5(7.8)$ & $12.0(5.7)$ & 0.344 & $7.8(4.0)$ & $11.2(6.0)$ & 0.167 & $-4.5(-17.3,8.3)$ & 0.410 \\
\hline
\end{tabular}

${ }^{\mathrm{a}}$ Mean (standard deviation)

bANCOVA adjusted for baseline values

'Data from 2 patients in immediate group and 6 in deferred group

\section{ACP content}

Data were available for 17 patients and their surrogates. No patients reported having made an advance decision to refuse treatment or a do not resuscitate document. Thirteen of 15 patients identified home as their preferred place of care at the end-of-life. In terms of their preferences for future treatment, patients were able to speak in broad terms (for example, that they would like to continue with dialysis; or that they would not want to be kept alive in a vegetative state; or that they would wish treatment to continue even if quality of life was affected) but many were unable to articulate preferences in specific hypothetical circumstances. Eight patients were content to trust their family in conjunction with the medical staff to take decisions in their best interests. Special requests centred on funeral and religious arrangements.
Agreement between the patient and their surrogate in terms of the patient's ACP preferences is presented in Table 2. We included patients and surrogates who made an ACP from both immediate and deferred groups. We considered the surrogate to have converged if their understanding moved towards the patient's views on at least one dimension of ACP. Overall, only ten surrogates participated fully in ACP. Of these, three converged and seven did not.

\section{Process evaluation}

This section begins with an overview of ACP implementation as described through process mapping, then provides detail on the experiences of patients, surrogates and staff. Trainers are identified as T1, T2 etc.; patients

Table 5 Staff costs to deliver ACP

\begin{tabular}{|c|c|c|c|}
\hline Resource use category & Staff time in minutes (SD) & Mean staff costs (SD) & Training fees \\
\hline Nephrologist introducing ACP per patient - completing patients $^{a}$ & $16.3(10.4)$ & $\mathbf{f} 29.34(18.72)^{i}$ & \\
\hline Nephrologist introducing ACP per patient - withdrawing patients ${ }^{b}$ & $13.8(8.0)$ & $\mathbf{E} 24.84(14.4)^{i}$ & \\
\hline Nurse introducing ACP per patient - completing patients ${ }^{c}$ & $19.0(9.4)$ & $\mathbf{E} 14.30(7.08)^{j}$ & \\
\hline Nurse introducing ACP per patient - withdrawing patients ${ }^{d}$ & $13.8(9.6)$ & $\mathbf{£} 10.38(7.23) j$ & \\
\hline Nurse delivering ACP per patient ${ }^{e}$ & $73.5(15)$ & $\mathbf{E 5 5 . 3 3 ( 1 1 . 2 9 ) j ~}$ & \\
\hline Training time per staff participant ${ }^{f}$ & 270 & $£ 365.26$ & $\mathbf{f} 80(n=10)$ \\
\hline Training time per expert patient ${ }^{\mathrm{g}}$ & 120 & $\mathbf{E} 100$ & $\mathbf{£} 40(n=5)$ \\
\hline Compensation per expert patient ${ }^{h}$ & & $\mathfrak{£ 5 0}$ & \\
\hline
\end{tabular}

adata from 11 patients

${ }^{\mathrm{b}}$ data from 12 patients

'data from 17 patients

ddata from 20 patients

${ }^{e}$ data from 13 patients ( 9 immediate and 4 deferred ACP)

$\mathrm{f}_{3}$ nephrologists and 7 nurses

${ }^{9} 5$ expert patients

${ }^{h} 1$ expert patient

'Cost per hour, 48-h week of a hospital based medical consultant - $£ 108$

jWeighted average of hourly rate of hospital based nurses. ACP Nurse pay bands: one band 7, four band 6, and one band 5 (one nurse was trained but did not implement ACP) [48] 
Table 6 Health system resource use and costs

\begin{tabular}{|c|c|c|c|c|c|c|c|c|c|c|c|c|}
\hline \multirow[t]{2}{*}{$\begin{array}{l}\text { Resource use } \\
\text { category }\end{array}$} & \multicolumn{2}{|c|}{$\begin{array}{l}\text { Immediate } \\
(n=13)\end{array}$} & \multicolumn{2}{|c|}{$\begin{array}{l}\text { Deferred }(n= \\
\text { 13) }\end{array}$} & \multicolumn{2}{|c|}{$\begin{array}{l}\text { Difference in resource } \\
\text { use }\end{array}$} & \multicolumn{2}{|c|}{$\begin{array}{l}\text { Immediate } £ \\
(n=13)\end{array}$} & \multicolumn{2}{|c|}{$\begin{array}{l}\text { Deferred } £ \\
(n=13)\end{array}$} & \multicolumn{2}{|c|}{ Difference in costs $£$} \\
\hline & Mean & SD & Mean & SD & Mean & $95 \% \mathrm{Cl}$ & Mean & SD & Mean & SD & Mean & $95 \% \mathrm{Cl}$ \\
\hline $\begin{array}{l}\text { Hospital admissions } \\
\text { (length of stay) }\end{array}$ & 10.46 & 14.05 & 9.08 & 10.37 & 1.38 & -8.61 to 11.38 & 16,769 & 22,514 & 14,550 & 16,626 & 2219 & $-13,801$ to 18,240 \\
\hline $\begin{array}{l}\text { GP practice or GP out } \\
\text { of hours service }\end{array}$ & 2.69 & 4.33 & 3.92 & 4.50 & -1.23 & -4.80 to 2.34 & 24.47 & 54.22 & 36.37 & 48.29 & -11.91 & -53.47 to 29.66 \\
\hline Formal home care & 13.08 & 39.89 & 6.46 & 11.02 & 6.62 & -17.07 to 30.30 & 87.54 & 238.6 & 118 & 244.5 & -30.46 & -226 to 165.10 \\
\hline Residential services & 0 & 0 & 0.23 & 0.6 & -0.23 & -0.59 to 0.13 & 0 & 0 & 41.25 & 102.56 & - & - \\
\hline Total & & & & & & & 16,881 & 22,586 & 14,742 & 16,639 & 2139 & $-13,919$ to 18,198 \\
\hline
\end{tabular}

as P1, P2; surrogates S1, S2; consultant nephrologists $\mathrm{CN} 1, \mathrm{CN} 2$; and ACP nurses ACPN1, ACPN2 etc.

\section{Process mapping}

This mapped ACP implementation from staff training through to the second ACP review. It helped reveal the complexity and challenge of ACP implementation, with each plan comprising 10 major and 15 minor processes, about a third of which were patient contacts. ACP nurses were associated with 21 of those processes and nephrologists with six (Fig. 2).

\section{Staff training for ACP}

Both doctors and nurses took part in half-day training for ACP with a multidisciplinary group of experienced, well-prepared trainers. The trainers expressed a thoughtful and nuanced view of the nature of ACP, embracing both practical and relational aspects of ACP. Having multidisciplinary representation from across a renal team that was already working together was thought to enhance the training.

'And I know everybody kind of really, kind of knew each other. But you had everybody. You had consultants there. You had nurses. You had...everybody was there to learn. And everybody chatted away. They talked and gave answers. And they really motivated to get this rolling, to get to talk to their patients about advance care planning.' (T1)

'So, I think when you get a group who have a focus on and also have a structure within which they are going to apply this knowledge, I think that makes a difference. It makes the training quite different.' (T2)

Trainers identified challenges in terms of the suitability of the venue and staff having opportunity to attend.

'I suppose it's just again that staff can actually get to it... shortages on the wards or in the community and they can't actually come to the training.' (T1)

Despite the insights and preparation of trainers, attending staff reported that training related to the ACP process was too brief and too general - focused on communication about prognosis rather than preparations for delivering ACP - but the training was still helpful in that it provided an opportunity for reflection and discussion.

'...it felt much more like an advanced communication course... but it wasn't about which I was hoping to be more about the nuts and bolts, the fundamentals, how do I actually set this up, how do we run it, how do we keep it going?' (CN1)

Table 7 Preference-based quality of life scores (utilities) and quality adjusted life years (QALYS)

\begin{tabular}{|c|c|c|c|c|c|c|c|c|c|c|}
\hline \multirow{4}{*}{$\begin{array}{l}\text { SF-6D } \\
\text { utility }\end{array}$} & \multicolumn{4}{|c|}{ Immediate $(n=13)$} & \multicolumn{4}{|c|}{ Deferred $(n=13)$} & & \\
\hline & \multicolumn{2}{|c|}{ Baseline (T1) } & \multicolumn{2}{|c|}{12 weeks (T3) } & \multicolumn{2}{|c|}{ Baseline (T1) } & \multicolumn{2}{|c|}{12 weeks (T3) } & \multicolumn{2}{|c|}{ Difference between groups } \\
\hline & Mean & SD & Mean & SD & Mean & SD & Mean & SD & Mean $^{a}$ & $95 \% \mathrm{Cl}$ \\
\hline & 0.69 & 0.09 & 0.68 & 0.11 & 0.68 & 0.15 & 0.71 & 0.13 & -0.05 & -0.15 to 0.05 \\
\hline \multirow[t]{4}{*}{ QALYS } & \multicolumn{4}{|c|}{ Immediate $(n=13)$} & \multicolumn{6}{|c|}{ Deferred $(n=13)$} \\
\hline & \multicolumn{4}{|c|}{12 weeks (T3) } & \multicolumn{4}{|c|}{12 weeks (T3) } & \multicolumn{2}{|c|}{ Difference between groups } \\
\hline & \multicolumn{2}{|l|}{ Mean } & \multicolumn{2}{|l|}{ SD } & \multicolumn{2}{|l|}{ Mean } & \multicolumn{2}{|l|}{ SD } & Mean & $95 \% \mathrm{Cl}$ \\
\hline & \multicolumn{2}{|l|}{0.12} & \multicolumn{2}{|l|}{0.07} & \multicolumn{2}{|l|}{0.13} & \multicolumn{2}{|l|}{0.07} & -0.005 & -0.06 to 0.06 \\
\hline
\end{tabular}

${ }^{\mathrm{a}}$ Difference between groups adjusted for baseline values 


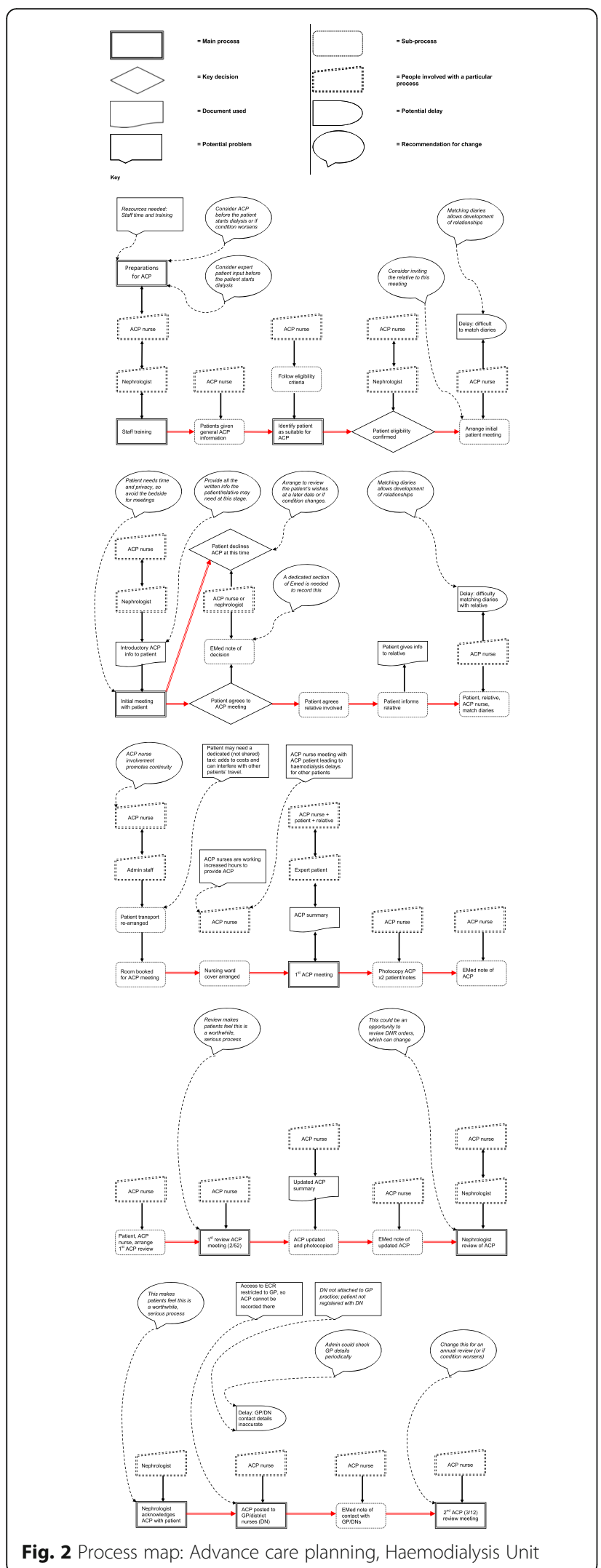

\section{Patient experiences of ACP}

Interviewed patients reported positive responses to ACP and felt that it had helped them discuss and plan for their final illness.

'Yeah, it was fine. We're just as we are today. I was absolutely at ease ... I thought it was done all right, like, you know, I was happy enough.' (P1)

'I didn't want to be resuscitated anymore...I wouldn't like to spend my last days in a nursing home.'(P2)

I feel happy enough with it. At least I have dotted the 'Is' and crossed the 'Ts'.... there was nothing unhelpful. I mean, the only thing was the withdrawing care, which I don't agree with at all under any circumstances. .... I want to live until I die. (P3)

ACP helped patients clarify their wishes with both staff and family, and so engendered a sense of relief.

Well, I think it forces you to .... think about it end of life and anything surrounding that. So, it helped me concentrate that-it helped me also stimulate a conversation with my wife .... I suppose I'm, yeah, more content with where I am, and... the direction I'm going. (P4)

'Probably relieved a wee bit, you know...because it made my son aware of my wishes....you're able to discuss things a bit better, like, you know, with my family' (P3)

Patients professed themselves at ease with involving their relatives in ACP and found this useful to help with the discussion.

Well, it's fine (including a relative in making the $A C P)$. It was fine. I mean, she and I have a great relationship.... And in fact, she had far more ideas than I had. (P3)

\section{Surrogate experiences of ACP}

Surrogates reported that ACP made them more aware of the patient's wishes and stimulated family discussions, which reduced uncertainty and gave them increased confidence that they would be able to make appropriate decisions.

II thought it'd probably be a good idea because it sorts things out and maybe decisions could be made that, that wouldn't be up to me, you know, that would probably take some of the onus off me from having to make some decisions.' (S1) 
II was able to tell the children, you know, that if anything happened everything in here is for dad, I wouldn't have probably been able to talk to them about it.' (S2)

This was the case even when the surrogate was not in agreement with the patient's wishes.

'He said, "Oh I want to be resuscitated as many times as possible", and I was like, "What? Why would you do that?" And he goes, "Because I do." He says, "I got a fighting chance," and I said, "But, you won't get a fighting chance because you may come back not right," and he says, "But that's what I want to be resuscitated," and I said, "Well your choice." Yeah, so that was fine ...I have respect for him ... I mightn't agree with what he wants but that I make sure that it is done because it's the way he wants it.'(S3)

\section{Experiences of ACP nurses and doctors}

When discussing ACP with patients, a wide range of non-medical aspects were covered, such as helping patients arrange where they would like to die and formulating wills but much less discussion on the dying process or realistic medical outcomes.

'So I had a few patients that had been talking about writing a will but until they actually did this plan, they haven't actually...I don't remember any patient really focusing on the final days or hours.' (ACPN1)

'They were very unrealistic: "Oh yes, I want the full everything, treatment." But you might not survive.' (ACPN2)

On the other hand, ACP could be a useful process for starting discussions.

I think ACP is about beginning the dialogue with patients about what is it that they would want to happen in certain circumstances. And sometimes that's relatively easy because it's easy to define things like dialysis or resuscitation and things. But other things are not so straightforward... Some people say I wouldn't want this if I had a stroke but you could have a stroke with very minimal changes or a stroke that was totally incapacitating so sometimes it's difficult to get the details right but I think it's very helpful in initiating conversations with people.' (CN2)

'...having a dialogue where we explore the wishes and fears of the patient...' (CN3)
As indicated by surrogates, ACP was thought to help relieve families of some of the burden of decisionmaking.

'... what do their loved ones think of the future? Are we all being reasonably realistic about the expectations of health for the future of that patient?... a way of broaching a difficult subject which is really just to tease out the fact that we all have finite lifespan" (CN4)

'It takes the burden off the family, they're not left in a visitor's room having to make a decision ... you have done everything that person would have wanted, so it would help with the whole grieving process rather than you're thinking, I made that decision, and was that the right decision, you know,' (ACPN3)

\section{Personal impact on staff}

Although staff were supportive of ACP, they found it personally challenging and felt that formal support should be made available.

'So, it is a very emotional process for people involved...it is also emotionally draining at times... [staff should be supported to] discuss their own issues they've had or things that have arisen during the process.' (CN2)

'...you're writing this in the event that something may happen to you that you can't voice your own wishes...And it suddenly made me think what I would like, what I wouldn't like, if you're ever in that position yourself.' (ACPN3)

\section{Factors thought to help or hinder ACP}

A key issue was the timing of ACP in relation to the patients' capacities and stage of disease. Those thought closest to death and therefore most in need of ACP were also those least able to engage with the burden of making a plan. Consequently, staff believed ACP should be offered earlier in the disease trajectory.

I think I would like to see it introduced at an earlier stage because as we've seen as the trial has progressed, patients withdrew mainly because they were sick, and then we had a lot of deaths too during the study so I think introducing that at an earlier stage in the patients journey, it's a better time for staff I think as well as patients.' (ACPN1)

Nurses and doctors collaborating effectively was thought to support a successful process. 
'...actually it's useful to have the consultant involved early on, and I think our uptake of the patients who were interested was slow until the consultants got involved, so I think the combination of the nurse involvement and a consultant together worked, seemed to work well, so that was a learning point for us.' (CN4)

It was acknowledged that ACP required a holistic and individualised approach, matching staff and resources to the particular needs of the patient.

'Patients] varied you know, in terms of like patients who were here a long time, you know, years, more than eight or nine and asking patients who were maybe only starting dialysis, you know, so they're very varied in terms of where they are...maybe [some] were more ready than others.' (ACPN1)

'...tailoring written information and tailoring verbal information is so important...some are comfortable reading, some are less comfortable reading...giving written information isn't a substitute for making sure that people actually fully understand what they're participating in.' (CN3)

A renal healthcare culture focused on treatment and cure, together with a societal culture of avoiding discussion of death was thought to hinder staff broaching prognosis, quality of life issues, and end-of-life care.

'Patients are] not always aware that it's a lifelimiting illness and they do need to think about the future.' (ACPN1)

'I don't think it's an area that has got a narrative around it, it's not something that people have been talking about, it's not part of docu-dramas or it's not on soaps about making advance care plans, so it's a reasonably foreign concept to patients...concerns perhaps about the legal basis of it, people are maybe a wee bit shy...' (CN3)

Organisational limitations in terms of lack of dedicated time and facilities were identified as key hindrances to ACP. In addition the communication infrastructure for ACP to be disseminated to community healthcare services was a concern.

'...in terms of coming back to implementing it, into routine practice, it takes time, it takes time to do it well. It requires recurrent review because the patients are going to change, their prognosis is going to change, their feelings are going to change, their wishes are going to change and you need to be able to come back to that.' (CN3)

'The biggest issue we found was that of time and finding an appropriate place ... to do it ... it's a very time-consuming thing in trying to fit it into normal practice...actually relied on us just doing it on our own time essentially.' (CN2)

'I just would want to make a comment about the dissemination of the plans which is not as straightforward as maybe people thought it would be. And that for the GPs are sent a copy, but the GPs got it recorded in a system that will not necessarily be available for everybody in the community to access.' (ACPN1)

\section{The burdens and benefits of implementing ACP as part of} a trial

Doing ACP in the context of a clinical trial had both benefits and burdens for clinical staff.

'Because we're nurses, and then a time factor as well, maybe come out of your break earlier, left break earlier to try and catch up with the documentation, so it was a time factor.' (ACPN3)

'...there seemed to be pages upon pages [of trial documentation]... (ACPN1)

'...actually the study made it helpful because you could tell patients that this was part of a study, that it wasn't that you had any particular concerns about them. And it's very difficult to gauge end of life in renal failure patients so it was a nice way to begin the conversation.' (CN2)

\section{Discussion}

Our study showed that recruitment of patients receiving haemodialysis and their surrogate decision makers into a trial of ACP is possible but not without its challenges. Recruitment was planned to take 3 months but took just over 6 months. Time needed for recruitment could have been shortened by more intensive deployment of clinical staff but this has resource implications. About a third of patients assessed for eligibility were excluded, and nearly half of those invited declined to take part. We had anticipated 25\% attrition but it reached $39 \%$ at 12 weeks and $53 \%$ at 24 weeks. This suggests that planning the sample size for a full trial would require the pool of potentially eligible patients to be at least three times larger than the number required for initial participation, and five times larger than the number required to complete data collection at 3 months. 
The challenges of recruitment to trials of palliative care (Boland et al., 2015) and ACP are well known (Sullivan, Garner and Dubbert, 2016; Stewart et al., 2018). Our ratio of recruitment was consistent with that of one small (Song et al., 2010) and one large trial (Song et al., 2015) of ACP among dialysis patients in the USA, but our figures for attrition following consent were higher than in the larger trial, which reached $30 \%$ at 2 months. This may be because our eligibility criteria meant we predominantly recruited frailer patients, and indeed, participating clinicians recommended approaching patients earlier in their disease trajectory.

Our study was designed as a deferred entry trial. A deferred entry trial has the advantages of a standard RCT because outcome data is collected from the deferred group before they receive the intervention, so allowing a comparison at that stage between those who have received the intervention and those who have not. It is also thought to encourage participation and reduce distress because all participants will eventually receive the intervention. A limitation is that this constrains the time at which the outcome data is collected as this is also the period that deferred patients must wait [25]. In our case, neither research assistants nor ACP nurses, nor interview data from participants reported patients being distressed by the offer of ACP, or by having to wait for the intervention, suggesting that a deferred entry trial may be unnecessary. The dialysis unit appears to lend itself to the ACP process in that it provides the opportunity for the development of supportive relationships with staff and regular contact to make an ACP.

Our sample was too small to be able to show differences in outcome measures between the immediate and deferred groups. Research assistants reported that patients were not distressed by the content of the data collection instruments but found the volume of data collected burdensome. In terms of the timing and frequency of outcome measures, there were minimal differences between scores at baseline and T2 (2 weeks), suggesting that these data do not add anything useful. Outcome measurement at three and 6 months post intervention may be more likely to capture immediate and longer-term differences between groups. The SHAR ED tool proved unsuitable in itself, largely because patients were inexperienced in shared decision-making, suggesting that the ACP intervention needs to include support for developing these skills and that other measures should be tried to assess shared decision-making with this population.

Detailed data on staff time spent on ACP related tasks were collected successfully along with the documentation of the ACP process. This estimate is probably conservative, as we did not anticipate all of the sub-processes of the intervention. Data on hospital admissions were readily available from routinely collected administrative data.

Fifteen patients - $22 \%$ of those approached - refused to take part in the trial because they objected to ACP or were concerned that it would distress their spouse, perhaps reflecting continued misgivings and misunderstandings about ACP in the UK. Less than half the patients were able to involve a surrogate and there was a very small effect on convergence of views on $\mathrm{ACP}$, perhaps because much ACP content was at a level of broad, non-specific preferences. This may partly be due to limitations in our intervention, which provided an opportunity for the patient and surrogate to discuss and plan future preferences but evidently did not succeed in helping patients to fully clarify their values or consider specific treatment choices. It may also be due to the inherent difficulty patients experience in imagining both possible medical conditions and decisions about complex major treatments they have not yet experienced [42]. Nevertheless, those who did take part were content to make an ACP, with both patients and surrogates feeling relieved to have done so and reporting reduced anxiety and - for surrogates - increased confidence that they could represent the patient's wishes, with some patients saying they would trust family to work with medical staff to take decisions in their best interests. This may point to focusing ACP interventions on preparation rather than prediction, preparing patients and surrogates to participate with clinicians in making the best possible in-the-moment medical decisions in light of the patient's values and goals. Traditional ACP outcomes may need to be supplemented with those that are defined by patients, exploring what they wish to achieve through ACP, such as starting this important conversation with family and clinical staff, clarifying values, and exploring the role of the surrogate $[42,43]$, as measured by instruments such as the ACP engagement survey [44].

\section{Conclusions}

A trial of ACP and its associated costs is feasible in patients receiving haemodialysis (subject to allowance for challenges in recruitment and retention of patients and their surrogates) and could provide a reliable estimate of the effects of ACP and whether this is a good use of resources. Based on recruitment and retention in our study, if 1200 patients were assessed for eligibility and invited to participate in a randomised trial, this would result in 400 being randomised, with 200 (100 in intervention and control groups) available 6 months later to be analysed for differences in ACP engagement. For example, this would give $90 \%$ power at the $5 \%$ level of significance to detect a mean increase of 0.5 on a 5 -point Likert scale using the 15-item Advance Care Planning Engagement Survey [45]. Given a mortality rate of $10 \%$ 
per year [46], 40 participants in each group would be expected to die during the 2 years after the intervention. This would give $80 \%$ power at the $5 \%$ level of significance to detect an increase in the proportion of patients whose wishes were known and respected at the time of death from 30 to 65\% [47]. Shorter follow up for this outcome would require a larger sample because of the smaller proportion of deaths among the randomised patients (for example doubling the sample size would allow follow up over just 1 year). Widening eligibility criteria to include younger (under 65 years of age) and less frail patients, together with special efforts to engage and retain surrogates would probably improve recruitment and retention. There are just 700 patients being dialysed in 6 units in NI, so recruitment would need to include three or four larger dialysis units from elsewhere in the UK. This would increase the generalisability of results and allow the inclusion of more patients from ethnic minorities.

Experienced nurses and doctors were able to deliver ACP on-site to an acceptable standard after training for only half a day, and with ongoing informal support from the research team. However, those with less experience might require more extensive training and formal ongoing support.

A significant proportion (45\%) of those invited to participate declined. About one third of these appeared to object to ACP in itself, with the remainder concerned about the impact on a spouse or the effort involved in answering research questions. Those who took part in the process evaluation professed themselves content with the process, excepting the involvement of expert patients. Therefore, whilst ACP seems to be acceptable to most patients in this population, as well as to participating clinical staff, issues of patient and surrogate understanding, and burden of research must still be addressed.

Further, the ACP intervention needs to be developed to include clarification of patients' values and preparation of patients and surrogates to participate in shared decision-making with clinicians. This in turn has implications for training and support for staff, which should be focused on helping them gain confidence in the human aspects and practicalities of the ACP process. Outcome measures can be a burden for patients, so these should be focused on important process-related (identifying a surrogate, clarifying values) and patient-centred outcomes; as well as measuring preparedness for decision-making for both patient and surrogate.

\section{Abbreviations}

ACP: Advanced care planning; ACPN: Advance care planning nurse; ADRT: Advance decision to refuse treatment; CHEERS: Consolidated Health Economic Evaluation Reporting Standards; Cl: Confidence interval;

CN: Consultant nephrologist; CORE 34: Clinical Outcomes in Routine
Evaluation; DNR: Do not resuscitate; ESKD: End-stage kidney disease; GP: General practitioner; IST 15: Isaacs Set Test; KDQOL-36 ${ }^{\mathrm{TM}}$ : Kidney Disease Quality of Life instrument - Short Form; NI: Northern Ireland; P: Patient; QUALY: Quality adjusted life years; SHARED: Patient Experience of Shared Decision Making; T: Trainer; UK: United Kingdom

\section{Acknowledgements \\ This work would not have been possible without the contributions of all the study participants and the nurses and nephrologists in the renal units. Members of the Northern Ireland Kidney Patient Association contributed to the implementation strategy for the advance care planning intervention. The Trial Steering Committee was chaired by Professor Vivien Coates of Ulster University. Special thanks to the ACP Nurses at the Regional Nephrology Unit, Belfast City Hospital, and the Renal Unit, Antrim Area Hospital, who provided invaluable insight, and support during the implementation phase.}

\section{Authors' contributions}

Research idea and study design: PO, HN, FM, KB; data acquisition: KN, PM, JS, RM, MM, TF; data analysis/interpretation: PO, HN, KN, TF; statistical analysis: CC, RM, KS; economic evaluation: RM, KS, PO; mentorship of PO: KB. Each author contributed important intellectual content during manuscript drafting or revision, accepts personal accountability for the author's own contributions, and agrees to ensure that questions pertaining to the accuracy or integrity of any portion of the work are appropriately investigated and resolved. The authors read and approved the final manuscript.

\section{Funding}

This work was supported by The Dunhill Medical Trust [grant number R428/ 0715]. Neither the funders nor Queen's University Belfast had any role in study design; collection, analysis, and interpretation of data; writing the report; and the decision to submit the report for publication.

\section{Availability of data and materials}

Deidentified data that underlie the results reported in this article are available to qualified researchers for approved scientific uses immediately following publication with no end date. Data access proposals should be directed to the corresponding author. The Trial Protocol is available on request.

\section{Ethics approval and consent to participate}

Ethical approval was provided by the Office for Research Ethics Committees, Northern Ireland. REC reference: 16/NI/0043; Protocol number: B16/06; IRAS project ID: 193402. All participants gave written informed consent.

ClinicalTrials.gov Identifier: NCT02631200; registered: 16/12/2015; https://clinicaltrials. gov/ct2/show/NCT02631200?term=NCT02631200\&draw=2\&rank=1

\section{Consent for publication}

Not applicable.

\section{Competing interests}

The authors declare that they have no competing interests.

\section{Author details}

${ }^{1}$ School of Nursing and Midwifery, Queen's University Belfast, Medical Biology Centre, 97 Lisburn Road, Belfast BT9 7BL, UK. ${ }^{2}$ School of Psychology, Ulster University, Cromore Road, Coleraine, Co. Londonderry BT52 1SA, UK. ${ }^{3}$ School of Medicine, Dentistry and Biomedical Sciences, Queen's University Belfast, Whitla Medical Building, 97 Lisburn Road, Belfast BT9 7BL, UK. ${ }^{4}$ Regional Nephrology Unit, Belfast City Hospital, 51 Lisburn Road, Belfast BT9 7AB, UK. ${ }^{5}$ Hull York Medical School, University of Hull, Allam Medical Building, Hull HU6 7RX, UK. ${ }^{6}$ Renal Unit, Antrim Area Hospital, Bush Road, Antrim BT41 2RL, UK. ${ }^{7}$ Centre for Public Health, Queen's University Belfast, Institute of Clinical Sciences, Royal Victoria Hospital, Belfast BT12 6BA, UK. ${ }^{8} \mathrm{NHMRC}$ Clinical Trials Centre, University of Sydney, Medical Foundation Building, 92-94 Parramatta Rd, Camperdown, NSW 2050, Australia. 
Received: 11 June 2020 Accepted: 26 October 2020

Published online: 13 November 2020

\section{References}

1. UK Renal Registry. UK Renal Registry 21st Annual Report - data to 31/12/ 2017 [Internet]. Vol. 3349. Britstol, UK; 2019. Available from: https://www. renalreg.org/publications-reports/.

2. Liyanage T, Ninomiya T, Jha V, Neal B, Patrice HM, Okpechi I, et al. Worldwide access to treatment for end-stage kidney disease: a systematic review. Lancet. 2015;385(9981):1975-82 [cited 2015 Mar 19] Available from: http://www.sciencedirect.com/science/article/pii/S0140673614616019.

3. Tonelli M, Wiebe N, Guthrie B, James MT, Quan H, Fortin M, et al. Comorbidity as a driver of adverse outcomes in people with chronic kidney disease. Kidney Int. 2015;88(4):859-66. https://doi.org/10.1038/ki.2015.228.

4. National Collaborating Centre for Chronic Conditions. Chronic kidney disease. London: Royal College of Physicians; 2008. p. 1-204.

5. Anderson S, Halter JB, Hazzard WR, Himmelfarb J, Horne FM, Kaysen GA, et al. Prediction, progression, and outcomes of chronic kidney disease in older adults. J Am Soc Nephrol. 2009;20(6):1199-209 [cited 2014 Oct 17] Available from: http://www.ncbi.nlm.nih.gov/pubmed/19470680.

6. Bikbov B, Purcell CA, Levey AS, Smith M, Abdoli A, Abebe M, et al. Global, regional, and national burden of chronic kidney disease, 1990-2017: a systematic analysis for the global burden of disease study 2017. Lancet. 2020;395(10225):709-33.

7. Neovius M, Jacobson SH, Eriksson JK, Elinder CG, Hylander B. Mortality in chronic kidney disease and renal replacement therapy: a population-based cohort study. BMJ Open. 2014;4(2):1-9.

8. Arulkumaran N, Szawarski P, Philips BJ. End-of-life care in patients with endstage renal disease. Nephrol Dial Transplant. 2012;27(3):879-81 [cited 2014 Jun 18] Available from: http://www.ncbi.nlm.nih.gov/pubmed/22379182.

9. Davison SN. Advance care planning in patients with chronic kidney disease. Semin Dial. 2012;25(6):657-63 [cited 2014 May 28] Available from: http:// www.ncbi.nlm.nih.gov/pubmed/23173893.

10. Axelsson L, Alvariza A, Lindberg J, Öhlén J, Håkanson C, Reimertz H, et al. Unmet palliative care needs among patients with end-stage kidney disease: a National Registry Study about the last week of life. J Pain Symptom Manag. 2018:55(2):236-44 Available from: https://www.scopus.com/inward/ record.uri?eid=2-s2.0-85038826057\&doi=10.1016\%2Fj.jpainsymman.2017.09. 015\&partnerlD=40\&md5=8b7b79a22b2ab676a2eee64f3a3d86ca.

11. Wachterman MW, Hailpern SM, Keating NL, Tamura MK, O'Hare AM. Association between hospice length of stay, health care utilization, and medicare costs at the end of life among patients who received maintenance hemodialysis. JAMA Intern Med. 2018;178(6):792-9 Available from: https://www.scopus.com/inward/record.uri?eid=2-s2.0-85048051816 \&doi=10.1001\%2Fjamainternmed.2018.0256\&partner $\mid \mathrm{D}=40 \& \mathrm{md} 5=54 \mathrm{f} 2$ a8e9b740c187585f9a334eb86ba8.

12. Luckett T, Sellars M, Tieman J, Pollock CA, Silvester W, Butow PN, et al. Advance care planning for adults with CKD: a systematic integrative review. Am J Kidney Dis. 2014;63(5):761-70 [cited 2014 Jun 11] Available from: http://www.ncbi.nlm.nih.gov/pubmed/24434187.

13. Mullick A, Martin J, Sallnow L. An introduction to advance care planning in practice. BMJ. 2013;347(October):1-6. https://doi.org/10.1136/bmj.f6064.

14. Bernacki RE, Block SD, American College of Physicians High Value Care Task Force. Communication about serious illness care goals. JAMA Intern Med. 2014;174(12):1994 [cited 2017 May 22] Available from: http://www.ncbi.nlm. nih.gov/pubmed/25330167.

15. Krouse RS, Rosenfeld KE, Grant M, Aziz N, Byock I, Sloan J, et al. Palliative care research: issues and opportunities. Cancer Epidemiol Biomark Prev. 2004;13(3):337-9 [cited 2017 May 22] Available from: http://www.ncbi.nlm. nih.gov/pubmed/15006905.

16. Houben CHM, Spruit MA, Groenen MTJ, Wouters EFM, Janssen DJA. Efficacy of advance care planning: a systematic review and meta-analysis. J Am Med Dir Assoc. 2014;15(7):477-89 [cited 2017 May 22] Available from: http:// www.ncbi.nlm.nih.gov/pubmed/24598477.

17. Brinkman-Stoppelenburg A, Rietjens JA, van der Heide A. The effects of advance care planning on end-of-life care: a systematic review. Palliat Med. 2014;28(8):1000-25 [cited 2014 Aug 10] Available from: http://www.ncbi. nlm.nih.gov/pubmed/24651708.

18. Department of Health. National service framework for renal services part two : chronic kidney disease, acute renal failure and end of life care. London: Department of Health; 2005.
19. National Institute for Health and Clinical Excellence. Chronic kidney disease quality standard: NICE; 2012. [cited 2014 Jul 1]. Available from: http:// publications.nice.org.uk/chronic-kidney-disease-quality-standard-qs5.

20. Crail S, Walker R, Brown M. Renal supportive and palliative care: position statement. Nephrology. 2013;18:393-400. [cited 2014 Aug 27]. https://doi. org/10.1111/nep.12064/full.

21. Lim CED, Ng RWC, Cheng NCL, Cigolini M, Kwok C, Brennan F. Advance care planning for haemodialysis patients. Cochrane Database Syst Rev. 2016; 7:CD010737. https://doi.org/10.1002/14651858.CD010737.pub2 Lim CED, editor [cited 2017 May 22]

22. CRD. Advance care planning [Internet]. York: Centre for Reviews and Dissemination; 2013. [cited 2015 Jan 27]. Available from: https://www.york. ac.uk/inst/crd/pdf/Advancecareplanning.pdf.

23. O'Halloran P, Noble H, Norwood K, Maxwell P, Shields J, Fogarty D, et al. Advance care planning with patients who have end-stage kidney disease: a systematic realist review. J Pain Symptom Manag. 2018;56(5): 795-807.

24. Craig P, Dieppe P, Macintyre S, Michie S, Nazareth I, Petticrew M. Developing and evaluating complex interventions: new guidance; 2008. Medical Research Council. Available from: https://mrc.ukri.org/documents/ pdf/complex-interventions-guidance/.

25. Higginson IJ, Booth S. The randomized fast-track trial in palliative care: role, utility and ethics in the evaluation of interventions in palliative care? Palliat Med. 2011;25(8):741-7 [cited 2014 Sep 10] Available from: http://www.ncbi. nlm.nih.gov/pubmed/21993806.

26. Evans CJ, Stone KA, Manthorpe J, Higginson IJ. MRC guidance on developing and evaluating complex interventions: application to research on palliative and end of life care. Methods Review 15 [Internet]. London: NIHR School for Social Care Research London School of Economics and Political Science Houghton Street London WC2A 2AE; 2013. 1-37 p. Available from: www.sscr.nihr.ac.uk.

27. SAGE \& THYME ${ }^{\Theta}$ [Internet]. 2019 [cited 2019 Jan 22]. Available from: http:// www.sageandthymetraining.org.uk/.

28. Gibbons E, Fitzpatrick R. A structured review of patient-reported outcome measures for people with chronic kidney disease, 2010. phi.uhce.ox.ac.uk. 2010. Available from: http://phi.uhce.ox.ac.uk/pdf/ElectiveProcedures/ PROMs_Oxford_Elective_Cardiac_012011.pdf.

29. Isaacs B, Kennie AT. The set test as an aid to the detection of dementia in old people. Br J Psychiatry. 1973 [cited 2014 Sep 26];123(4):467-70. https:// doi.org/10.1192/bjp.123.4.467.

30. Evans C, Mellor-Clark J, Margison F, Barkham M, Audin K, Connell J, et al. CORE: clinical outcomes in routine evaluation. J Ment Health. 2000;9(3):24755. https://doi.org/10.1080/713680250\&magic=crossref\%7C\% 7CD404A21C5BB053405B1A640AFFD44AE3.

31. Evans C, Connell J, Barkham M, Margison F, McGrath G, Mellor-Clark J, et al. Towards a standardised brief outcome measure: Psychometric properties and utility of the CORE-OM. Br J Psychiatry. 2002;180(01):51-60 [cited 2019 Jan 4] Available from: https://www.cambridge.org/core/product/identifier/ S0007125000160453/type/journal_article.

32. GEM. Patient experience of shared decision making (SHARED) [Internet]. Gridenabled measures database. 2014 [cited 2014 Oct 17]. Available from: https:// www.gem-measures.org/public/MeasureDetail.aspx?cat=2\&mid=1517\&tab=0.

33. Julious SA. Sample size of 12 per group rule of thumb for a pilot study. Pharm Stat. 2005[cited 2014 Aug 6];4(4):287-91. https://doi.org/10.1002/pst.185.

34. Hertzog MA. Considerations in determining sample size for pilot studies. Res Nurs Health. 2008;31(January):180-91.

35. Vickers AJ, Altman DG. Statistics notes: analysing controlled trials with baseline and follow up measurements. BMJ. 2001;323(7321):1123-4. [cited 2013 Dec 6]. https://doi.org/10.1136/bmj.323.7321.1123.

36. Statacorp. Stata 14 | Stata [Internet]. 2015. Available from: https://www.stata. com/stata14/.

37. Husereau D, Drummond M, Petrou S, Carswell C, Moher D, Greenberg D, et al. Consolidated Health Economic Evaluation Reporting Standards (CHEE RS) statement. BMJ. 2013;346:f1049 [cited 2019 Mar 28] Available from: http://www.ncbi.nlm.nih.gov/pubmed/23529982.

38. Ivankova NV, Creswell JW, Stick SL. Using mixed-methods sequential explanatory design: from theory to practice. Field Methods. 2006;18(1):3-20.

39. Antonacci G, Reed JE, Lennox L, Barlow J. The use of process mapping in healthcare quality improvement projects. Health Serv Manag Res. 2018;31(2): 74-84 [cited 2019 Jan 22] Available from: http://www.ncbi.nlm.nih.gov/ pubmed/29707978. 
40. Eldridge SM, Chan CL, Campbell MJ, Bond CM, Hopewell S, Thabane L, et al. CONSORT 2010 statement: extension to randomised pilot and feasibility trials. BMJ. 2016;355:15239.

41. Hall RK, Luciano A, Pieper C, Colón-Emeric CS. Association of Kidney Disease Quality of Life (KDQOL-36) with mortality and hospitalization in older adults receiving hemodialysis. BMC Nephrol. 2018;19(1):11 [cited 2019 Jan 9] Available from: http://www.ncbi.nlm.nih.gov/pubmed/29334904.

42. Sudore RL, Fried TR. Redefining the "planning" in advance care planning: preparing for end-of-life decision making. Ann Intern Med. 2010;153(4): 256-61.

43. McMahan RD, Knight SJ, Fried TR, Sudore RL. Advance care planning beyond advance directives: perspectives from patients and surrogates. J Pain Symptom Manag. 2013;46(3):355-65. https://doi.org/10.1016/j. jpainsymman.2012.09.006.

44. Sudore RL, Stewart AL, Knight SJ, McMahan RD, Feuz M, Miao Y, et al. Development and validation of a questionnaire to detect behavior change in multiple advance care planning behaviors. PLoS One. 2013;8(9):e72465. https:// doi.org/10.1371/journal.pone.0072465 [cited 2019 Feb 11], Xie Z, editor.

45. Sudore RL, Heyland DK, Barnes DE, Howard M, Fassbender K, Robinson CA, et al. Measuring advance care planning: optimizing the advance care planning engagement survey. J Pain Symptom Manag. 2017;53(4):669-681. e8 [cited 2019 Feb 11] Available from: http://www.ncbi.nlm.nih.gov/ pubmed/28042072.

46. Steenkamp R, Pyart R, Fraser S. UK Renal Registry 20th Annual Report: Chapter 5 Survival and Cause of Death in UK Adult Patients on Renal. Replacement Therapy in 2016: National and Centre-specific Analyses. Nephron. 2018;139(suppl1):117-50. https://doi.org/10.1159/000490963.

47. Detering $K$, Hancock A, Reade M, Silvester W. The impact of advance care planning on end of life care in elderly patients: randomised controlled trial. BMJ. 2010;340(7751) [cited 2014 Aug 27] Available from: http://www.bmj. com/content/340/bmj.c1345.

48. Royal College of Nursing. NHS pay scales 2017-18 [Internet]. [cited 2019 Nov 8]. Available from: https://www.rcn.org.uk/employment-and-pay/nhs-pay-scales-2 017-18\#tab4

\section{Publisher's Note}

Springer Nature remains neutral with regard to jurisdictional claims in published maps and institutional affiliations.

Ready to submit your research? Choose BMC and benefit from:

- fast, convenient online submission

- thorough peer review by experienced researchers in your field

- rapid publication on acceptance

- support for research data, including large and complex data types

- gold Open Access which fosters wider collaboration and increased citations

- maximum visibility for your research: over $100 \mathrm{M}$ website views per year

At $\mathrm{BMC}$, research is always in progress.

Learn more biomedcentral.com/submissions 